\title{
“'SE MUERE GALLO BUENO!”. PELEAS, SOCIALIDAD Y VIOLENCIA GALLERAS EN COSTA RICA
}

\author{
Onésimo Rodríguez Aguilar
}

Recibido: 19/08/2014 Aceptado: 26/01/2015

\begin{abstract}
Resumen
Este texto resume parte del proceso de trabajo de campo etnográfico desarrollado con varios jóvenes galleros en la provincia de Heredia en Costa Rica. ${ }^{1}$ Se intenta develar algunas de las lógicas de sentido de los sujetos, por ejemplo, lo que llamo socialidad gallera (cierto código de interacción relacionado con lo subterráneo y lo vivencial), la forma de aprehensión simbólica y material de los animales y las diferentes formas de violencia que se reproducen en las galleras "clandestinas".

Palabras clave: peleas de gallos; violencia; galleras clandestinas; socialidad.
\end{abstract}

\begin{abstract}
This text summarizes the process of ethnographic fieldwork with several young cockers developed in the province of Heredia, Costa Rica. It attempts to unravel some of the logical senses made by subjects in several ways for example, what I call sociality gallera (certain code of interaction associated with the underground and the experiential), the symbolic and material apprehension of the animals as mell as the different forms of violence that breed in underground arenas.
\end{abstract}

Key words: cockfighting; violence; clandestine cockfighting; sociality.

\section{Introducción: algunas precisiones etnográficas}

La idea de reflexionar sobre la dinámica de las peleas de gallos obedece, en primer lugar, a la necesidad de abordar una temática muy poco tratada por la academia costarricense (algunos antecedentes serán expuestos más adelante) y, en segundo lugar, a la intención de discutir algunas premisas totalizantes difundidas por diferentes medios de comunicación que desarrollaban aproximaciones fugaces, ligeras e irreflexivas; en donde los galleros aparecen como sujetos malignos, figuras casi demoniacas que matan de manera arbitraria e indiscriminada a los animales (Rodríguez y Alpízar, 2014).

La sospecha general es que existen ciertas omisiones en el tratamiento de ese tipo de información periodística, vinculadas a las demandas de las empresas mediáticas de 
este país (idem.), que olvidan la necesidad de reflexionar acerca de las relaciones sociales, históricas y políticas de los sujetos que participan en este tipo de actividades.

Así, en Costa Rica, las peleas de gallos datan, por lo menos, de mediados del siglo XIX ${ }^{2}$ (historicidad ausente en los medios), lo cual es muy importante, pues permitirá establecer, más adelante, que las dinámicas galleras son prácticas que materializan tradiciones y formas culturales complejas e intricadas.

De esta forma, algunas de las interrogantes que se discuten en el presente escrito son: ¿qué es lo que en realidad acontece en estas peleas de gallos?, ¿quiénes son esos galleros $^{3}$ que están siendo abordados despectivamente por varios sectores de la opinión pública del país? y ¿cómo es y qué significa para ellos la práctica de las peleas de gallos? Para el abordaje de estas preguntas se llevó a cabo un intenso proceso de observación etnográfica (de enero del 2012 a enero del 2014): un convivio con los galleros no solo en los redondeles clandestinos, sino también, en otros contextos como los lugares en donde crían a los gallos, espacios públicos y domésticos, etcétera.

Los galleros de La Gotera ${ }^{4}$ (nombrados en este artículo con los seudónimos: "Felo", “Caballo", “Pelota”, “Pava” y "Manolo") son jóvenes de edades que oscilan entre los 20 y los 28 años, todos ellos viven con sus padres y hermanos (familias nucleares), se dedican a diversas actividades como la construcción y el polaqueo ${ }^{5}$, trabajan en fábricas, o bien, como taxistas informales o formales.

Con ellos, se visitaron varias galleras del Valle Central, en las cuales siempre se pudo constatar la asistencia de jóvenes, quienes no solo presenciaban las peleas, sino que también criaban sus propios gallos. Lo que interesa rescatar acá es que cuando se les preguntaba ¿por qué jugaban y criaban gallos? las respuestas eran variadas, pero en todos los casos habían referencias claras a tres situaciones: 1 . Simplemente les gustaba, 2. Era una actividad que desarrollaban desde niños, 3. Se divertían mucho, incluso algunos dijeron que los gallos significaban una "pasión" para ellos. ${ }^{6}$

Estas ideas de la pasión y la conjunción se retomarán en un apartado posterior que desarrolla, a partir de los datos etnográficos, el concepto de socialidad gallera (Maffesoli, 2009, 2007, 1996), el cual supone una especie de estructuración subterránea de este tipo de actividades vinculadas a una contraposición estética a lo instituido (racional), la eterna lucha entre lo dionisíaco y lo apolíneo (es decir, lo carnavalesco y lo racional). Esto para reafirmar el lazo colectivo y orgiástico que se da entre muchos de los sujetos que integran estas dinámicas proscritas e imaginadas al margen de lo socialmente convenido.

Antes de este apartado se presentan varias secciones que ordenan la lógica interpretativa del texto, claro está, tomando como referencia la información etnográfica. En la primera de ellas se presentan algunas precisiones generales acerca de lo que es La Gotera y los redondeles clandestinos (galleras), espacios que se regulan y ordenan a partir de disposiciones normativas (explícitas o implícitas), lo cual los acerca a la lógica estructural de la sociedad. La extensa descripción desarrollada en esta sección tiene 
por objetivo, como ya se mencionó, evidenciar el orden característico de estos lugares, pero, además, ofrecer un panorama detallado de lo que son las galleras y las peleas de gallos, en vista de que la literatura consultada aborda poco este tipo de circunstancias y lógicas estéticas.

En la siguiente sección y siguiendo con la exposición del material etnográfico, se cuestionan algunas ideas encontradas en el clásico estudio de Geertz (1989). Acá se discuten algunas premisas muy sugerentes de este autor, por ejemplo, lo relacionado con la consideración de que los gallos son extensiones fálicas del orgullo masculino de los galleros y, además, la idea geertzsiana de que "las peleas son reales solo para los gallos".

Finalmente, se presenta la sección de conclusiones, en donde se insiste en la dimensión cultural de las peleas de gallos y en la necesidad de ir más allá de las alusiones que desarrolla la prensa sobre este tipo de fenómenos que son complejos y acerca de los cuales es irresponsable hablar "ligeramente".

\section{La Gotera}

Hoy La Gotera no existe. Después de la trágica muerte de "Caballo" (uno de los jóvenes galleros, propietario del establecimiento) en mayo de 2013, los chicos decidieron repartirse los gallos, las gallinas y demás pertenencias para terminar de desalojar la gallera; tomaron esta decisión porque no querían recordarle a la madre de "Caballo", con su presencia, la ausencia de su hijo.

La Gotera era, pues, el lugar donde criaban sus gallos; una especie de guardería de gallos ubicada en una pequeña finca al norte del centro de Heredia. Había unas 50 jaulas, varias de ellas ocupadas por los gallos que en ese momento estaban cuidando y entrenando. Además de gallos y gallinas, tenían cerdos en sus porquerizas, caballos en sus respectivas cuadras, algunas cuantas casas de los familiares cercanos a "Caballo" y una entrada de unos 50 metros que daba a la calle pública. 
Figura 1

LA GOTERA

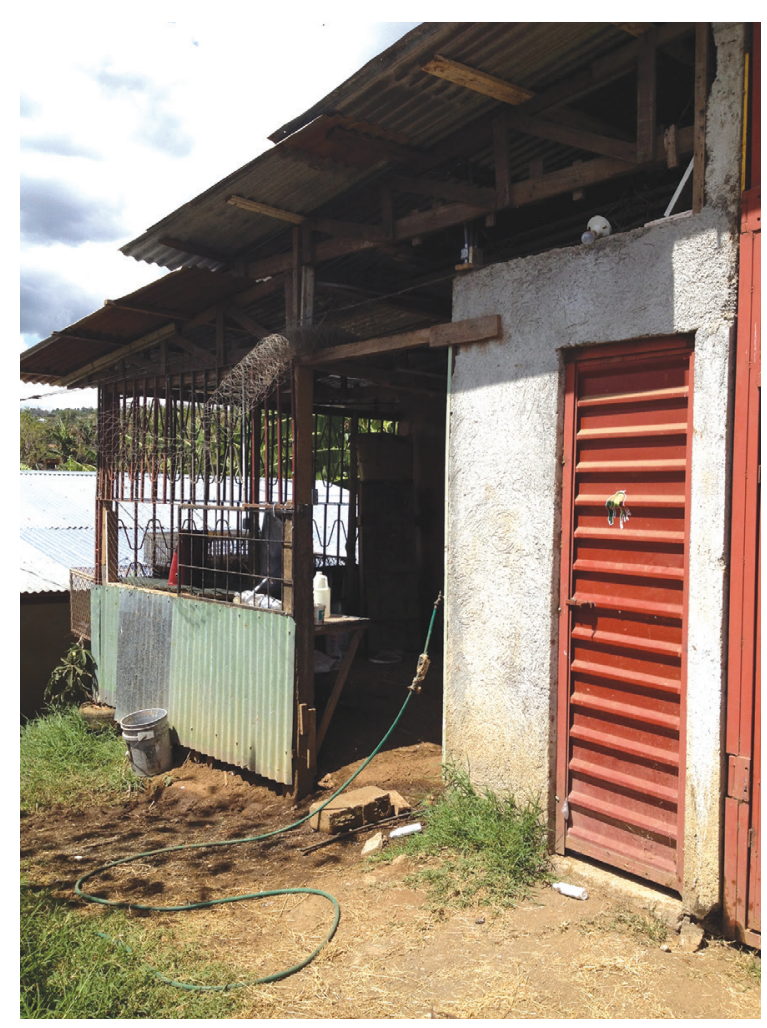

Fuente: Rodríguez, 2014.

"Felo", “Pelota”, “Caballo" y "Pava” se encargaban de los gallos. La preparación del animal para la pelea iniciaba meses antes. Según dicen ellos, desde que el gallo es pichón se le da un cuido especial: comida específica, pastillas estimuladoras del crecimiento y tonificación, entrenamientos con otros gallos de la gallera y corte de las crestas y plumas, para finalmente, semanas antes de la pelea, exponerlos a diario al sol con la intención de endurecerle la piel al animal y así reducir la posibilidad de que en la contienda el gallo reciba un "espuelazo" mortal. Toda esta preparación del ave recién salida del cascarón hasta su primera pelea tarda un año completo. Esto se pudo constatar con otros galleros que asisten a los eventos en los redondeles clandestinos, también llamados galleras.

Ellos tienen por costumbre, cuando salen de la gallera hacia el redondel donde jugarán sus gallos, dejar abierta la jaula de los animales que llevan a pelear, 
la razón: "dejamos las puertas abiertas para que el gallo regrese" (conversación informal con "Felo"), lo cual llama la atención sobre una dimensión supersticiosa. Si dejan la puerta cerrada es mal augurio, porque se le está imposibilitando al gallo el regreso a su casa.

Después de esta dinámica ceremonial, meten a los gallos en unas maletas especiales, hechas a base de cuero y con algunos orificios para que el animal pueda respirar, luego los acomodan dentro de los carros en los que se trasladarán al redondel. En ese momento, inicia el viaje hacia la gallera, regularmente acompañado de bebidas alcohólicas, chistes, risas y relatos de experiencias épicas en relación con peleas pasadas donde sus gallos han salido vencedores.

\section{Redondeles clandestinos}

Se tuvo la oportunidad de visitar un total de cinco galleras clandestinas: tres ubicadas en Alajuela, una en Heredia y otra en San José. Una de ellas, la de San José, estaba cerca de una vía concurrida de una localidad del norte capitalino. Las otras, por el contrario, se localizaban en fincas, en zonas un tanto alejadas de los centros poblacionales de los lugares mencionados y con relativa dificultad de acceso, aun así, era evidente que la gente que reside en los alrededores de la gallera sabía de su existencia. Si bien estos espacios se erigen en sectores de acceso complicado, no quiere decir que estén complemente aislados de la experiencia vecinal-comunal.

Las galleras (redondeles) son los espacios en donde se juegan gallos y se reúnen personas, fundamentalmente hombres, para observar y participar en las contiendas. Estos sitios por lo general están construidos de restos de madera y latas de zinc, dando la impresión de una estética dominada por la precariedad: telas de arañas inundan las esquinas inalcanzables del recinto, pisos de tierra o con rellenos asistemáticos de concreto, espacios carentes de pintura y techos con múltiples goteras. Y es así porque son redondeles improvisados, los cuales quizás se tengan que trasladar a otro lugar para evadir el control policial.

Dentro, estas cinco galleras, no cambian mucho su ordenación y organización espacial. La zona central, regularmente, está dominada por una circunferencia con una alfombra superpuesta (lugar donde pelean los gallos, manchada de sangre y excremento), a su alrededor se levanta un complejo desordenado de tablas dispuestas y clavadas a vigas de madera levantadas como soportes que funcionan como graderías. Acá pueden congregarse entre 100 y 300 personas dependiendo del tamaño del redondel. En la periferia próxima a la circunferencia, las primeras locaciones para los "aficionados" es una zona VIP, donde los asistentes pagan un derecho por dicho privilegio; las demás locaciones, más alejadas de la "arena de combate" no precisan cancelar dinero extra. ${ }^{7}$ 
En los alrededores a la zona central de la gallera (el redondel) hay varios aposentos. Los galleros utilizan los que están debajo de la gradería para preparar a sus aves, ahí les ponen las espuelas, que son unas puntas afiladas hechas de carey de aproximadamente una o dos pulgadas. El gallo lleva dos espuelas, una en cada pata, las cuales funcionan como espadas que sirven para infringir mayor daño al animal contrario. Alrededor de estos espacios donde se prepara a los gallos están las jaulas, allí los jugadores guardan a sus animales mientras presencian otras peleas o esperan el momento preciso de su contienda.

Más alejado de esta zona central se ubica un área de cocina, atendida por mujeres, que se encargan de preparar diversos alimentos que serán consumidos por los asistentes al evento. Entre esta área de cocina y el redondel (arena de combate) se ubica una pila, donde se lavan los gallos heridos para eliminarles el exceso de sangre producto de las heridas sufridas en el enfrentamiento. Los gallos muertos se apilan cerca de esta zona o son tirados fuera del recinto.

Antes de las peleas, los gallos son pesados. La romana o báscula está dispuesta en la parte posterior del redondel, ahí se reúnen los galleros para observar cuál ave coincide en peso con la propia. Según "Felo", el único lugar en donde un gallero defiende a su gallo es en la báscula, la razón de esta sentencia es que el dueño del animal debe tratar de pactar un combate con un gallo del mismo peso; pues pequeñas diferencias en esta delicada medición pueden ser letales a la hora de la contienda. "Felo" me decía que, además del peso, un buen gallero, debe saber a cuál contrincante "echarle su gallo", y ponderar elementos como: altura del gallo oponente, pues si el contrincante es más alto lleva ventaja, ya que "ve más"; además, si el gallo propio es tuerto, en la negociación, el contrincante debería de darle una o dos libras de ventaja, es decir, un gallo tuerto tiene una desventaja física notoria, de esa forma, se puede negociar que el otro gallo sea incluso un par de libras más liviano. Aun así, en este asunto de pesos y pesajes no hay reglas fijas, se ha podido observar que algunos galleros que "echan" a su gallo en contra de un oponente significativamente más pesado, y el primer gallo termina ganando la pelea.

Después de la báscula, y pactada la pelea, los gallos son "alistados": se les lleva al espacio debajo de la gradería donde se les pone cuidadosa y rigurosamente las espuelas; esta parte de la preparación previa a la pelea tarda varios minutos y los galleros son muy obsesivos con este proceso. El gallo debe quedar bien armado. No se pueden permitir omisiones de ningún tipo. Durante este "aliste" algunos galleros ya se notan nerviosos o ansiosos por lo inminente de la pelea en la que su animal puede resultar mal herido o, incluso, muerto. Regularmente, no es el dueño quien "alista" al gallo, es más bien otro gallero de confianza, especializado en espuelas, quien asume este delicado proceso. La precisión debe ser milimétrica, las espuelas deben tener el ángulo preciso, dependiendo de la forma en que juega el ave, si ataca arriba, si ataca abajo, si juega por afuera, etcétera. 


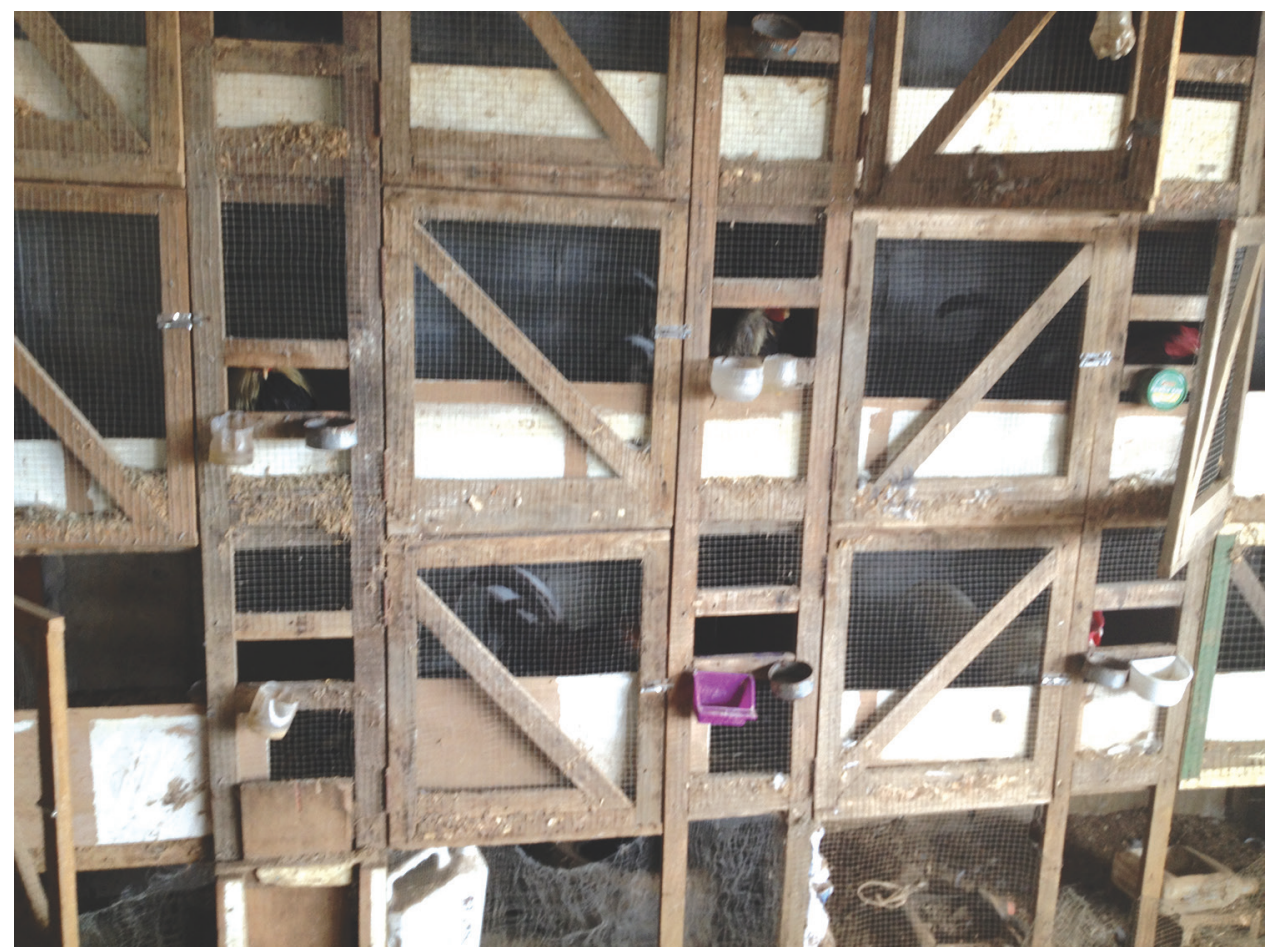

Fuente: Rodríguez, 2014.

Posterior al "aliste", los gallos son llevados a la arena, a la zona alfombrada dentro del redondel. Ahí, en dicha circunferencia, están únicamente los dos galleros con sus respectivos animales y uno o dos jueces, quienes velan por el cumplimiento de las normas dispuestas. Algunas reglas observadas en todas las galleras visitadas son las siguientes:

1. Las peleas duran máximo 10 minutos, los jueces se encargan de "vigilar" el tiempo.

2. Antes de que transcurran esos 10 minutos, el gallo que mate o hiera de gravedad al oponente, al punto de no recibir respuesta, es el triunfador.

3. Los animales son revisados por los jueces, en especial las espuelas dispuestas en el gallo; con ellas se pincha un limón para eliminar residuos de algún posible veneno que pueda perjudicar al oponente (esta regla supone desconfianza, que cuestiona el código de honor-caballeresco que se analizará más adelante). 
4. Los galleros pueden cambiar una o dos espuelas de sus gallos en medio del combate cuando estas se quiebran, pero solo pueden pedir cambio una sola vez cuando se trata de la espuela derecha, cuando es la izquierda (todos los gallos son zurdos) pueden cambiarla las veces que quieran.

5. Después de iniciada la pelea, si se nota que alguno de los dos gallos no ha "tirado" (no ha atacado), por un periodo de dos minutos, el oponente gana.

6. Si uno de los dos gallos "se corre" (huye), antes del minuto de iniciado el enfrentamiento, se declara empate.

7. Si uno de los dos gallos "se corre" después del minuto de iniciada la pelea, la victoria es para el oponente.

8. Durante la pelea, los galleros no pueden tocar a ninguna de las dos aves, si lo hacen es para detener la contienda, lo cual convierte en ganador al gallo contrario.

9. Si se acaban los 10 minutos de pelea, los jueces tienen la obligación de colocar a ambos gallos frente a frente, si los dos quedan en pie se concede empate, si uno de los dos no se levanta, pierde.

10. Es permitido gritarle a los gallos, regularmente, son frases de aliento y motivación.

11. Las apuestas (sobre las que se hablará en detalle más adelante) se pactan entre los dos galleros antes de iniciada la pelea, el dinero se le entrega a uno de los jueces, quien lo resguarda hasta el final.

Este conjunto de reglas (que no están escritas en ninguna parte) muestran que, a pesar de ser una actividad sancionada por la ley ("ilegal"), existe un conjunto de disposiciones (generalmente acatadas por todos los galleros) que organizan las riñas.

\section{Del honor al cuento de Geertz}

Que un gallo "se corra" o se "agache" durante una pelea significa uno de los peores descréditos para el gallero. En unos cuantos de los combates observados, algunos animales, al primer espuelazo de su oponente, salían corriendo alrededor del redondel; en una ocasión una de las aves se saltó la barda de la arena, renunciando de manera automática al enfrentamiento con su oponente; evidentemente, el animal contrario es el que triunfa, pero más allá de esto, que un ave propia huya es una especie de humillación simbólica para el dueño del gallo.

En una de las peleas observadas, uno de los gallos de "Felo" perdió, pero perdió "mal", es decir, no batalló, no luchó; según su dueño, el ave tuvo miedo. "Felo" estaba muy molesto con el animal, al final lo recogió de la arena y se lo llevó para La Gotera (aunque muchas aves terminan apiladas y muertas en una de las esquinas de los redondeles), según él, solamente para matarlo al otro día. "Felo" decía que le daba vergüenza ese gallo, “igallo hijueputa, ni las espuelas usó! y para colmo todo el mundo le iba al chile [gallo contrario]". 
Pareciera que el gallo puso en duda la honorabilidad de "Felo" y eso era lo que en realidad le molestaba al joven gallero, por eso, durante todo el camino de regreso a casa, como si estuviera rebobinando en la mente el video de la pelea, le iba lanzando improperios al gallo. Pareciera ser que el gallo que se aprecia es el gallo "bueno", el que pelea y da batalla aunque pierda. El gallo "agachado" es descartado y eliminado; porque, como dice "Felo", “¡cómo no come ese hijueputa y tras de eso malo!", es decir, no se puede seguir invirtiendo en un gallo malo.

Así, el mayor orgullo de un gallero es criar sus propios gallos y que estos animales sean buenos, es decir, que peleen hasta el final, sin "agacharse" y sobre todo, que ganen combates. "Felo" me contaba que él al inicio compraba gallos, pichones, y se encargaba de cuidarlos hasta que tuvieran edad para pelear (un año aproximadamente), sin embargo, decidió abandonar esta práctica de compra de pichones, pues, según él, "nadie te va a vender lo bueno, te venden lo malo", entonces decidió "tener" sus propios gallos y criarlos, es decir, desarrollar una línea propia. Este joven afirmaba que "es lindo cuando un gallo suyo gana, mae, es lindísimo, uno sale de la arena todo envalentonado, pero es más lindo todavía cuando el gallo es suyo, cuando usted fue el que lo sacó de su línea y a nadie se lo compró, es un sentimiento indescriptible”. Al respecto de la riña de gallos en Bali, Geertz argumenta:

Pero la intimidad de los hombres con sus gallos es más que metafórica. Los varones balineses, o en todo caso una gran mayoría de los varones balineses, se pasan una gran cantidad de tiempo cuidando a sus gallos favoritos, alimentándolos, hablando con ellos, probándolos unos contra otros o simplemente contemplándolos en una mezcla de rapto admirativo y profunda ensoñación (1989: 344).

Geertz (1989) continúa explicando la significancia de estos animales para los balineses: "buena parte del espíritu de Bali se manifiesta en un reñidero de gallos. Pues sólo aparentemente son gallos los que combaten; en realidad son hombres" además, "para cualquiera que haya estado en Bali un tiempo prolongado es evidente la profunda identificación biológica de los varones con sus gallos" (343); de esta forma,

los gallos son considerados como penes separables, que obran por su cuenta, órganos sexuales ambulantes con una vida propia (...) está fuera de toda duda el hecho de que los gallos son símbolos masculinos por excelencia (...) los gallos son expresiones simbólicas o manifestaciones del yo del dueño (el yo masculino y narcisista desde el punto de vista esópico) (1989: 343-344).

Es sugerente esta reseña interpretativa que hace Geertz de su proceso de observación etnográfica en esta isla de Indonesia. Lo que llama la atención es la proximidad de dicha realidad balinesa con la que viven los galleros a los que se ha venido haciendo referencia. El gallo es una especie de extensión fálica del honor del 
dueño, algo así como una proyección imaginaria de la masculinidad del hombre que cría y juega gallos en un redondel. Por eso, los gallos "malos" son descartables y los "buenos", referenciados incluso con cierta épica. ${ }^{8}$ La profunda relación de la que habla Geertz (1989), la reproducen los galleros con las aves "buenas", las que pueden brindarle al hombre ese estatus sobresaliente delante de los demás criadores. Por eso, las grandes batallas son recordadas con orgullo. El gallo hace que el gallero sea reconocido, máxime cuando el gallo mata o gana rápido; así, el animal que vence a su oponente en menos de un minuto es catalogado como un excelente gallo por su dueño y amigos cercanos.

Una de las primeras veces que visité una gallera fue con "Felo", "Caballo", "Pava" y "Pelota". Debo confesar que mi impresión inmediata fue de sorpresa y algo de extrañeza: una multitud gritándole a dos gallos 9 que estaban peleando en la arena, además de la sonoridad de los gritos, incrementados por una extraña acústica aumentada por las latas de zinc, hacían que el clima interno fuera sugerentemente intenso, y los espuelazos de los gallos se esparcían en el aire, aunque muchos lograban clavarse en las corporalidades de las aves, que para ese momento ya sangraban copiosamente; cada vez que los gallos se abalanzaban en contra de su oponente una nutrida cantidad de plumas volaba por los aires, mientras el duelo de las cuchillas seguía reproduciendo un particular sonido a modo de espadas que se entrecruzan estrepitosamente con la intención de herir al rival.

Los gritos de la muchedumbre agolpada en las gradas del redondel son variados: “jsi le tira, lo mata!", le dice un gallero a su oponente al ver que su gallo va ganando la contienda, el otro dueño le contesta: "ique lo mate!", con una especie de desidia fingida, porque claro está, nadie quiere que su gallo pierda y menos aún que sufra y muera. Sin embargo, la sangre, las plumas y los latigazos de las espuelas son parte del juego que los dueños y demás concurrentes deciden jugar.

Otros asistentes gritan: “jese pollo ya se murió, carajo!", o bien, “jse muere gallo bueno!", haciendo referencia a que un gallo muy bueno y combatiente está perdiendo la contienda, lo cual significa una especie de aceptación de la capacidad del oponente que no hace más que anunciar la valía del gallo propio, quien finalmente está ganando, es decir, "si el otro es bueno, el mío es mejor".

En las peleas se juega más que dinero (apuestas); en ese sentido acá es necesario volver al aporte clásico de las peleas de gallos en Bali. Geertz homologa la riña con la noción de juego profundo que retoma de Bentham, precisamente porque en dichas dinámicas se arriesga tanto que resulta irracional que los hombres "se lancen a semejante juego"; además, en estas competencias "el dinero es menos una medida de utilidad que un símbolo de alcance moral" (1989: 355).

En los juegos profundos, en los que se apuestan grandes cantidades de dinero, lo que está en juego es algo más que las ganancias naturales: la consideración pública, el honor, la dignidad, el respeto, en una palabra (aunque en Bali este vocablo tiene una compleja carga de significación) 
el status (...) Debo de hacer notar enseguida que esto no significa afirmar que a los balineses no les importe el dinero o que les de lo mismo perder quinientos ringgits que perder quince. Semejante conclusión sería absurda. Precisamente porque el dinero importa e importa mucho en esta sociedad en modo alguno antimaterialista es por lo que cuanto más dinero se arriesga tantas más cosas diferentes se arriesgan, como orgullo, el equilibrio, la serenidad, la masculinidad, aunque sólo sea momentáneamente, pero todas esas cosas se arriesgan también públicamente (Geertz, 1989: 355-356).

La significancia de las peleas para los galleros es medular. Muchas son las menciones que se hacen durante las contiendas que se relacionan con el orgullo, pero además, con la jerarquía entre los dueños de los gallos, aunque, como menciona Geertz (1989), la pelea "no cambie el status de nadie" y no se pueda "ascender en la escala jerárquica por haber ganado en la riña de gallos" (ibid.: 364).

En pocas ocasiones la atmósfera incitadora de la competencia se intensifica, los dueños de los gallos que están peleando se cruzan algunas frases amenazantes y se dan algunos encontronazos, aunque nunca se observó que los galleros se fueran a los golpes o se produjera algún evento más serio. "Felo" me contaba una anécdota de cuando "Caballo" estaba vivo, "una vez en San Ramón" (empezó a contar "Felo"):

habiamos jugado 3 o 4 gallos contra los mismos maes, unos galleros de mucha plata de Guanacaste, la cosa es que les habíamos matado todos los gallos mae, oiga, todos, y cuando ganamos el último gallo, el quinto, "Caballo" se tiró desde la parte de arriba de la gradería y les celebró la victoria en la cara a los maes estos de Guanacaste; entonces uno de esos maes sacó un revólver y se lo puso a "Caballo" en la cabeza, entonces "Caballo" le agarró el chopo ${ }^{10}$ y se lo puso en el pecho y le dijo, "si me va a matar, máteme", entonces otro compa, Jeffrey, saltó desde arriba y le gritó al guanaco, ${ }^{11}$ si le va a pegar a "Caballo" tiene que pegarme a mí, le quitó el revólver y lo retó a los pichazos ${ }^{12}$... al final pararon la vara y no pasó a más (Conversación informal con "Felo").

Regularmente, cuando se dan este tipo de encontronazos entre galleros, los demás asistentes de la gallera los exhortan a que no lo hagan, que no lleven sus diferencias a los puños o a situaciones más serias, se suele decir, "caballeros, ya estuvo... vamos a pelear gallos, acá los únicos que pelean son los gallos". Lo cual es interesante, porque según esta premisa, los gallos pelean para que los hombres no lo hagan, el juego termina siendo una válvula de escape, violenta claro está, en donde el hombre proyecta sus sentimientos agresivos en el gallo, pero no los objetiva (al menos en forma de golpes) en otra persona. 


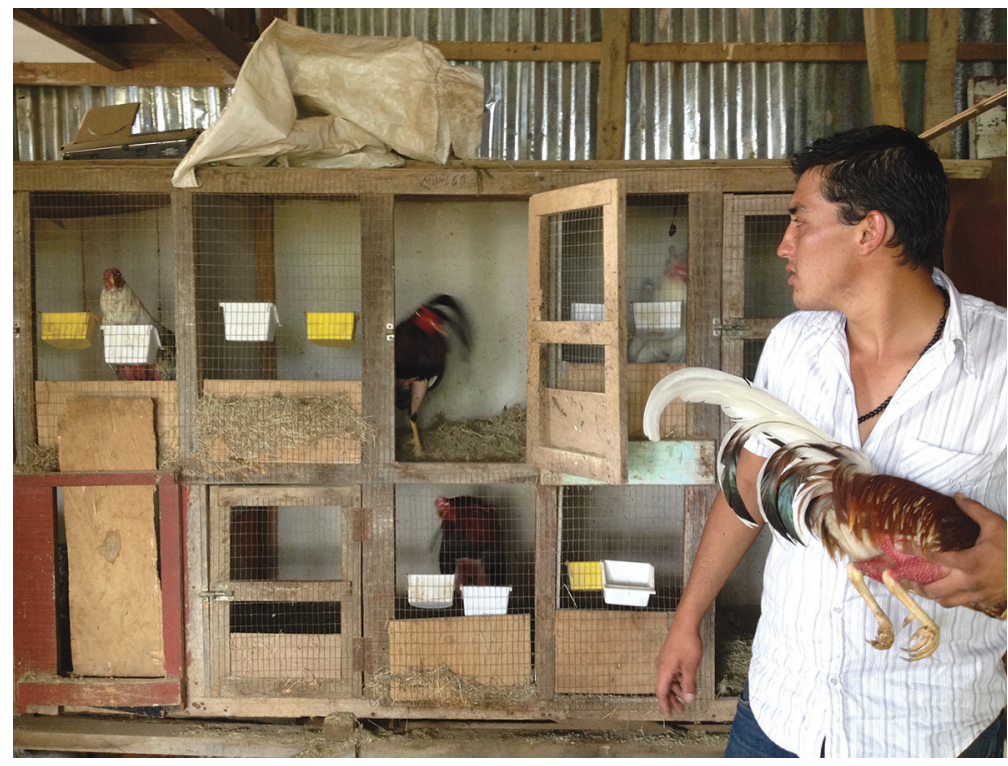

Fuente: Rodríguez, 2014.

Esto es sugerente, porque si bien los galleros no dirimen sus diferencias a "pichazos", sí hay muchas muestras de violencia simbólica y verbal (violencia latente) dentro del redondel, por ejemplo, al calor de las peleas se dicen muchas frases de clara alusión machista e incluso homofóbica, por ejemplo: “iHágale tonta, hágale que le echaron bueno!", “Siga peleando polla, siga cortando!", “iPelee hijueputa, no se quede parado!", “'Gallo playo, no corta ni picha!”, “Vamos gallinita, vamos, usted es mejor que él!". Estas frases y otras más son dichas a los gallos que están combatiendo, al respecto es interesante la deformación feminizada cuando se refieren al gallo con los términos "tonta" o "gallinita", o bien, la mención del gallo "playo" que "no corta ni picha", es decir, no ataca bien.

Entonces, si bien los galleros no se van a los golpes por la existencia de un código tácito de no agresión física entre "caballeros", la observación etnográfica refleja que en las peleas existen tensiones entre los galleros que se resuelven de manera tangencial, reproduciéndose una violencia simbólica muy evidente; el punto es que, pareciera que para los galleros, la violencia se suele tipificar desde una dimensión física (la cual está tácitamente prohibida), y no se suele considerar como violencia el conjunto de frases y tensiones que se reproducen durante las contiendas. ${ }^{13}$ De este modo, los gallos no son los únicos que pelean, los hombres también lo hacen. Acá se debe puntualizar 
una significativa diferencia con la propuesta del antropólogo interpretativo, pues, para él, la riña de gallos

es "realmente real", sólo para los gallos; no mata a nadie, no castra a nadie, no reduce a nadie a la condición de animal, no altera las relaciones jerárquicas entre las personas, ni modifica las jerarquías; ni siquiera redistribuye el dinero de una manera significativa (Geertz, 1989: 364).

Los hombres en las peleas no cambian su jerarquía cotidiana después de ganar o perder una pelea, pero dentro de la gallera, los "buenos" galleros son reconocidos, incluso por sus más feroces oponentes. Cuando un gallero "bueno" incursiona con su animal en brazos hacia dentro del redondel, se pueden escuchar diversos comentarios como "ese gallero es bueno", "tiene muy buenos gallos" o "es muy buen criador", y si bien no dirimen sus diferencias a machetazos o a "pichazos", sí reproducen una serie de violencias que no son sencillamente olvidadas como quizás lo supone Geertz al manifestar que las peleas son "realmente reales sólo para los gallos" (1989: 365).

Lo de Geertz más bien pareciera el recuento de una historia, un cuento que llama la atención y causa sospecha por su coherencia desde el inicio hasta el final, en donde los balineses se ven incluso como sujetos inocentes incapaces de llevar sus diferencias más allá de la riña. Geertz acá es enfático, la funcionalidad de la riña de gallos, si es lícito llamarla así, resulta interpretativa, pues "es una lectura de la experiencia de los balineses, un cuento que ellos se cuentan sobre ellos mismos" (ibid.: 368).

Esto, evidentemente, no ocurre con los galleros que hemos estado describiendo. Ellos, a diferencia de los individuos plasmados por Geertz en su etnografía en la isla indonesia, son sujetos que eligen y deciden dirimir de manera violenta sus relaciones. La misma pelea de gallos, su matriz agresiva, que implica a dos animales peleando y un público expectante que vitorea porque uno u otro gallo mate a su rival es muestra de ello. La pelea de Geertz es una historia relatada para ser creíble, sin contradicciones de clase y de poderes que deja en la misma ubicación a los balineses; habría que preguntarle a un gallero si la dedicación con que crían a sus gallos durante años, incluso, desde que son niños, puede ser interpretable como una "pintura" o un "cuento" sobre ellos mismos, como lo menciona Geertz; es decir, una interpretación ficticia, un simulacro de sus realidades.

Entonces, si la riña de gallos es tan importante en Bali, como lo menciona este autor al inicio de su texto, aunque al final le da el mote de "pintura" o "cuento", ¿cómo es que tiene implicaciones únicamente durante la pelea misma? ¿Cómo es "realmente real" solo para los gallos y no para los hombres?

Es difícil pensar, como lo aseguran muchos galleros, que las relaciones con sus homólogos se den en un ambiente de completa cordialidad y caballerosidad, aunque en parte sea cierto. Hay galleros con quienes, por ejemplo, los chicos de La Gotera tienen relaciones cercanas, incluso, algunos son amigos y sus gallos nunca pelean entre 
sí. "Felo" le decía a un amigo: "Somos de los mismos, ¿¿cómo los vamos a echar?!" ante la invitación (en tono de broma) de este otro joven a pelear entre sí. Esta situación dice mucho, pues pareciera que solo se pelean gallos con personas imaginadas como oponentes o no-amigos, es decir, efectivamente, existen rencillas entre galleros fundamentadas en competencias pasadas donde, quizás, se perdió algún "buen gallo".

En una ocasión, en medio del desarrollo de una pelea, uno de los galleros pidió espuela, es decir, exhortó al juez a que parara la contienda pues, según él, su gallo había perdido el arma derecha (reclamo al que tienen derecho según la normativa gallera que se aportó más arriba). El gallo no había perdido ninguna espuela y todas las personas en el redondel lo sabían; el gallero pidió espuela para "darle aire" a su gallo que estaba siendo masacrado por su oponente $y$, en consecuencia, perdiendo la contienda. Después de la revisión del juez, la pelea continuó... a los pocos minutos de reanudada, este mismo gallo, que estaba siendo derrotado, perdió, ahora sí, la espuela derecha. El gallero no podía pedir esa espuela, pues ya lo había hecho, solamente podía solicitar la espuela izquierda. El truco de pedir espuela sin ser necesario le costó al gallero una pelea que de todas formas tenía perdida. Este relato se ofrece para evidenciar que en ocasiones las relaciones entre galleros no son tan honorables y que se presentan momentos de transgresión del código de caballerosidad del que tanto se precian los hombres que juegan gallos. Esto sin mencionar la regla número 3 de los combates que se explicó más arriba, en donde se pincha un limón con la espuela del gallo para evitar que estas armas hayan sido envenenadas.

Estas personas crían, alimentan, gastan dinero y tiempo en un gallo durante por lo menos un año, sabiendo que hay posibilidades de que el animal muera en la primer pelea. "Felo" dice que "así es esto, así es esta vara", sin embargo, la relación de los galleros con sus gallos dista de ser distanciada como para aceptar la pérdida de forma tan natural; hay personas que cuidan a sus gallos como si fueran niños, evidentemente saben que no lo son, pero les muestran una ternura muy sugerente; "Felo", por ejemplo, se suele dirigir a sus gallos así: “Hola gallinita, ¿cómo está?, ¿todo bien, papi?”, con un tono de ternura casi paternal. Con lo anterior se intenta decir que cuando un gallero pierde un gallo, suele perder una extensión de sí, además, las pérdidas siempre son dolorosas, por eso, se puede refutar acá esa idea de que las relaciones entre galleros siempre son cordiales y que los únicos que pelean realmente son los gallos. 


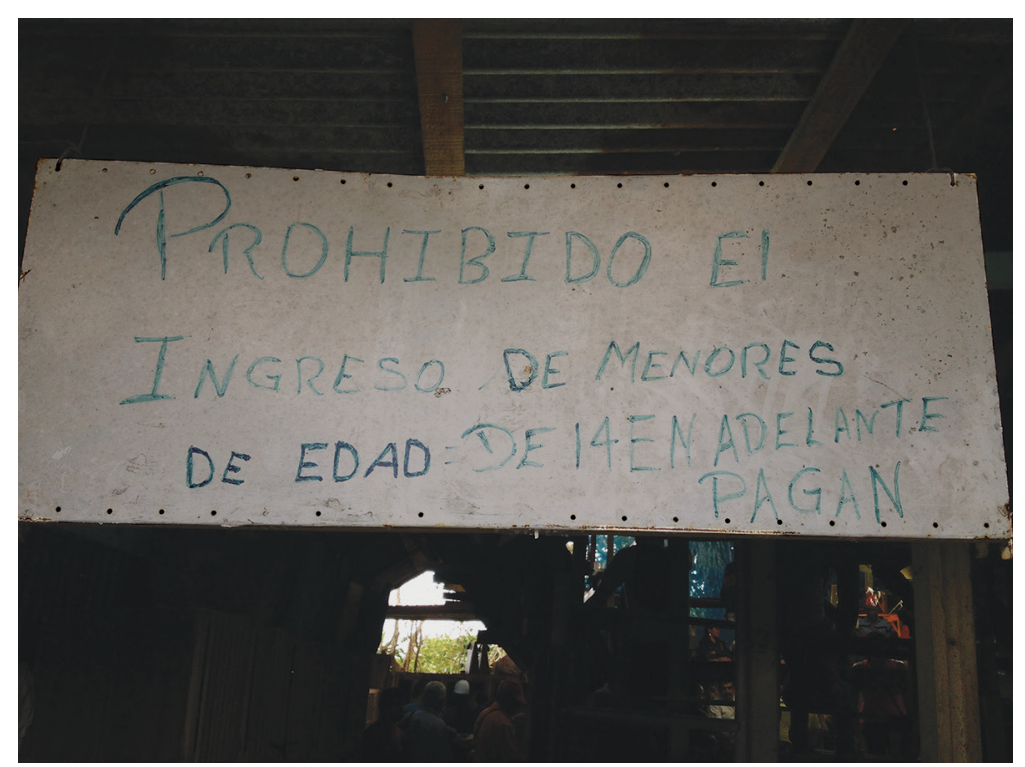

Fuente: Rodríguez, 2014.

\section{La socialidad gallera y la vida social del gallo}

Muchos de los galleros besan a sus gallos antes de la pelea, les hablan y estimulan para que peleen con coraje y valentía, incluso se puede observar que algunos dueños, al final de la contienda, se meten la cabeza ensangrentada del gallo en la boca para tratar de alivianar sus heridas.

Este curioso cariño por el animal está relacionado con una dinámica económica que parece ser trascendental en la lógica gallera: la apuesta. La apuesta es una actividad que, en muchos casos, determina la dinámica en el redondel. ${ }^{14}$ Nunca, durante el trabajo de campo, se jugó un gallo sin que dejara de mediar alguna cantidad de dinero. De lejos, parecería que este sentido económico es el que finalmente moviliza las ansias subjetivas de los dueños de los gallos. Sin embargo, hay que mirar con más atención.

Hay dos tipos de apuestas, la primera se da entre quienes asisten, antes y durante la pelea. Las personas de la gradería (que no necesariamente llevan gallos a combatir), apuestan entre sí mirándose a los ojos: pactan la cantidad de dinero por medio de señales hechas con las manos (debido al intenso ruido) o, si la persona con la que están apostando está cerca, con gritos: "voy 5 mil al chile" grita un hombre no identificado 
en la gradería; en la parte posterior de la misma alguien le responde, “iyo voy!”. Regularmente, la persona que pierde va hacia donde el vencedor a pagar la deuda; otras veces, el que gana se dirige hacia el opositor para cobrar el dinero. Durante la investigación, no se observó que los galleros o los asistentes tuviesen algún tipo de conflicto por este tipo de dinámica económica, pues la gente en estos lugares suele cumplir el compromiso adquirido, lo cual remite a un conjunto de disposiciones o normas tácitas que, regular y efectivamente, los asistentes a las galleras cumplen (como las leyes que se expusieron más arriba).

La segunda forma de apuesta se da entre los dueños, quienes suelen reproducir esta dinámica de forma diferente. En el caso de los jóvenes de La Gotera (y muchos de los otros galleros), después de pesar al animal y antes de pactar la pelea ("cazar" la pelea), negocian con el gallero contrario para establecer cuál es el monto por el que pelearán sus gallos, después de esto, los chicos hacen una "banca", una especie de contribución solidaria entre los amigos, para que no le corresponda a uno solo poner la totalidad del dinero. Alguno colabora con 10 000.00, otro con 5000.00 y alguien más, con otros 10000.00 colones, así se crea un fondo que permite poner a combatir el gallo para evitar que alguno de ellos gaste todo su dinero en una sola apuesta.

Cuando el gallo del "equipo" gana, la celebración es de todos, hay gritos, alegría y abrazos entre ellos; “jse lo dije, hijueputa, que íbamos a ganar, se lo dije!”, le dijo "Felo" a "Pelota" en una de las peleas realizadas en una gallera en Alajuela. Cuando pierden, evidentemente, las reacciones son todo lo contrario; pues recogen al gallo, lo lavan y si está vivo y vale la pena llevárselo a la casa lo hacen, si no lo dejan apilado con los otros gallos muertos de la "velada combativa".

Esto sugiere un conjunto complejo de solidaridades que reproducen cierta lógica de socialidad, término que indica la prevalencia de una

...centralidad subterránea; poco importa el término. Se trataba de atraer la atención sobre esta fuerza interna, que precede y funda el poder bajo sus distintas formas. Me parece que es esta "fuerza" la que está presente en el neotribalismo contemporáneo. Después de la dominación del "principio de logos", el de una razón mecánica y predecible, el de una razón instrumental y, estrictamente, utilitaria, asistimos al retorno del "principio del eros". ;Eterno combate entre Apolo y Dionisio! (Maffesoli, 2009: 27).

Este neotribalismo subterráneo se refiere a cierta capacidad de algunos grupos sociales contemporáneos de vivir, cotidianamente y en colectivo, momentos lúdicoextáticos, más allá de la racionalidad social funcionalista que se torna, en ocasiones, inquisidora; es, el retorno de lo dionisiaco, de ahí la alusión, en la cita anterior, al "eterno combate" entre lo apolíneo (racional) y lo dionisíaco (carnavalesco). Cabe resaltar que esta capacidad de experimentar la intensidad del momento (como lo hacen muchos galleros en las peleas de gallos), sugiere cierta revitalización del lazo colectivo (de ahí 
que los chicos junten dinero entre todos para poder "jugar" sus gallos), una socialidad festiva que sirve de argamasa para la conjunción de los sujetos; claro está que esta socialidad puede y debe ser violenta, no hay otra forma de erigir institucionalidades; más aún, no hay violencia irracional.

Esta conjunción que se ha denominado socialidad implica un "estar-juntos”, es decir, una lógica de placer y de goce "del mundo tal cual es" (ibid., 28), que puede "valorizar lo sensible, la comunicación, la emoción colectiva, y será por lo tanto más relativa, completamente dependiente de los grupos (o tribus) que estructura como tales; será entonces una ética, un ethos, que proviene de abajo" (Maffesoli, 2007: 21), de lo subterráneo, pues, precisamente, estas prácticas se cristalizan, muchas veces, más allá de lo legal, de lo normativo, encontrando resquicios de enunciación y estructuración en los abismos de los mundos proscritos. Quizás sea ese carácter extranormativo y subterráneo, implicado con esta experimentación común a la que se ha llamado socialidad gallera, lo que le otorga a la práctica ese vitalismo pujante que se manifiesta en los redondeles: la vivencia de un juego, en ocasiones desbordado, que se reproduce y que más bien pareciera verse fortalecido con las atribuciones de "ilegalidad" que le dan la institucionalidad y otros sectores sociales.

"Felo" comentaba que en estos redondeles clandestinos, espacios de reproducción de socialidad, se suelen organizar torneos en los que hay premios sustantivos para los mejores gallos y las mejores peleas, regularmente, el primer premio de la jornada se lo lleva el gallo que mató o le ganó al contrincante en el menor tiempo registrado durante el día. En uno de estos eventos, un gallo ganó su contienda en 10 segundos: le propinó un espuelazo mortal al oponente, haciendo ganar a su dueño un total de 200000.00 colones, solo por haber sido el vencedor más rápido del día. En diciembre, según "Felo", se organizan torneos de hasta 1000000.00 de colones para el gallo "más rápido" del evento.

El gallo entra en la paradoja de objeto amado y odiado. Cuando gana, se le quiere, pero además se le demuestra cariño; cuando pierde y pierde mal, se desecha, con desprecio e incluso con enojo por ser un gallo que "no corta", "que no es fino, sino refinado", es decir, no es puro (genéticamente hablando), porque según los galleros, entre más puro, mejor el animal para el combate.

"Felo" contaba la historia de uno de sus gallos, uno de los primeros animales que él tuvo. Para él, era un gallo ejemplar, pues peleaba y seguía cortando hasta el final, aunque estuviera malherido; “Felo" dice que este gallo ganó peleas estando "muerto", es decir, al encontrarse gravemente herido el ave terminaba ganando, con un golpe de gracia, la contienda. Este gallo le ganó un combate al propietario de una empresa muy importante en Costa Rica, en uno de los eventos organizados en una gallera del occidente del Valle Central, incluso, este señor (de mucho dinero) al final de la pelea, cuenta "Felo", le ofreció comprarle el gallo en una cantidad nada despreciable, pero el joven se negó. Según cuenta, el gallo significaba 
mucho para él como para venderlo: "acababa de ganarme 150 mil con él, ¿cómo lo iba a vender? No podía", relataba "Felo". El gallo siguió ganando, en total, ganó aproximadamente 15 peleas; pero lo que sí recuerda es que terminó "retirando" al gallo, no lo puso a combatir más dejándolo solo como padrote, con el cual esperaba sacar más gallos finos. "Nunca volví a tener un gallo como ese", cuenta "Felo" con nostalgia. Si uno le preguntara a cada uno de los galleros, contarían historias similares: un gallo paradigmático que les hizo ganar dinero, pero sobretodo, mucho respeto.

Esta ambivalencia se manifiesta en las peleas que se extienden por mucho tiempo; en ellas, cuando el público considera que ambos gallos han batallado, están "tablas" (empates) y en relativa igualdad de condiciones (es decir, con heridas similares), la gente empieza gritar: “iDense las manos, galleros!”, para instar a los dueños a recoger a sus respectivos gallos y declarar empatada la contienda, "no es necesario que los gallos sufran más" dicen los espectadores, como queriendo demostrar cierta sensibilidad y comprensión para con el sufrimiento de las aves, sentimiento que se apaga no más al empezar el siguiente duelo y vitorear para uno de los gallos mate al otro.

Figura 5

“TORMENTA", GALLO DE PELEA

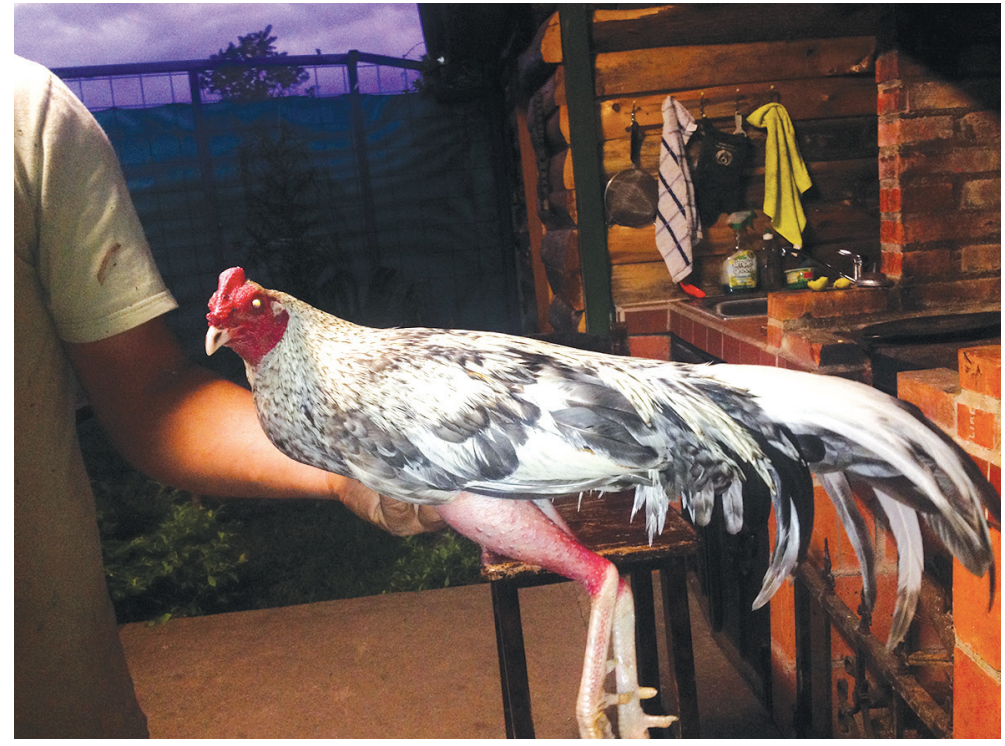

Fuente: Rodríguez, 2014.

La metáfora en la que podemos pensar acá es la del coliseo romano: una multitud que puede, en momentos específicos, decidir el destino de quienes combaten por "humanidad". Así, los galleros en ocasiones hacen caso de la exhortación del público, 
otras veces no es así y continúan hasta el final del duelo (los 10 minutos reglamentarios), esperanzados en que su gallo venza sorpresivamente al rival, situación que no sucede con frecuencia.

De este modo, se intenta decir que la vida social del gallo es mucho más compleja que la monocalificación de objeto mercantil, utilizable y desdeñable a partir de una lógica de producción específica que piensa únicamente en el costo-beneficio. El gallo no es solo mera mercancía, sino que, retoma, aprehende y resimboliza varias facetas. En un año de crianza y entrenamiento, tiempo que tarda la puesta a punto del animal para su primer pelea, el "objeto" se manifiesta cambiante, porque así lo experimenta el dueño. La lógica de interiorización del animal por parte del gallero fluctúa: se compra (pichón) o se "produce" en el lugar de crianza, se le da alimento, suplementos alimenticios, se le cuida y se le entrena con mucho esmero; dicho proceso genera una cierta alianza entre el gallero y su gallo, aunque claro, el dueño sabe que está preparando su animal para luchar no para "verlo", como diría "Felo". Así, la pelea cristaliza el momento culmen que todo gallero espera: saber cómo responde su animal en una contienda. Es decir, si se acepta la idea de que el gallo es una extensión fálica del orgullo masculinizado del hombre, se tendría que aceptar que el animal no es mera "cosa" intercambiable, al menos no durante toda su trayectoria.

Para Appadurai (1991), las "cosas" poseen una trayectoria que no está dominada exclusivamente por la producción, es decir, el comportamiento de los objetos no debe ser pensado únicamente bajo la ecuación mercancía-dinero-mercancía, o bien, dinero-mercancía-dinero; para Appadurai, la fase mercantil es solo una más dentro de la construcción de los objetos, pues estos tienen una vida social que no se limita a su momento productivo, en este sentido, se debe tomar en cuenta los intercambios, las distribuciones, además de los afectos y las emociones con que la gente aprehende cualquier tipo de "cosa". Una vez interiorizada, una cosa puede dejar de ser simple mercancía para convertirse en algo con valor de uso (emocional incluso), pero desprovista de valor de cambio; lo cual no quiere decir que esa "cosa" no pueda retornar a su fase mercantilizada.

A pesar de nuestro propio enfoque de las cosas esté necesariamente condicionado por la idea de que las cosas no tienen otros significados sino aquellos conferidos por las transacciones, las atribuciones y las motivaciones humanas, el problema antropológico reside en que esta verdad formal no ilumina la circulación concreta, histórica de las cosas. Por ello, debemos seguir a las cosas mismas, ya que sus significados están inscritos en sus formas, usos y trayectorias. Es sólo mediante el análisis de estas trayectorias que podemos interpretar las transacciones y cálculos humanos que animan a las cosas. Así, aunque desde un punto de vista teórico los actores codifican la significación de las cosas, desde una perspectiva metodológica son las cosas-en-movimiento las que iluminan su contexto social y humano (ibid.: 19). 
Lo anterior sugiere que los objetos tienen una vida social determinada por las dinámicas y las apropiaciones de las personas. Entonces, para Appadurai, "las cosas pueden entrar y salir del estado mercantil" (ibid.: 29), es decir, como se ha dicho, los objetos (en este caso los gallos) no estarían condenados a vivir una trayectoria eminentemente productiva de intercambiabilidad, sino que, su historia estaría sobredeterminada por circuitos y dinámicas sociales específicas desde que nacen y hasta que mueren.

Incluso, se podría hablar de la funcionalidad de estos animales, por ejemplo, servir de contenedor proyectivo de los deseos de los hombres (quienes buscan ser percibidos con respeto, ser sujetos de orgullo, honor y caballerosidad). Más que cosas meramente intercambiables, los gallos simbolizan una significancia singular (la cual en cierta forma es reconocida por los propios dueños): suponen la capacidad de realización imaginaria de algunas imposibilidades de los hombres. Estos no pueden acceder a ciertos reconocimientos externos si no es a través de la figura del animal, precisamente porque no pueden "despedazarse" a espuelazos, ni batirse en duelo con otros hombres, esto es mostrar su "hombría" en situaciones agresivas límite, pues además la sociedad castigaría severamente dichas disposiciones; de esta forma, sus ansias de violencia (al menos la violencia física) son redireccionadas hacia las aves, en las que se deposita el papel de portadoras de ciertos delirios colectivos. La vida social del gallo resulta determinante para la estructuración de la socialidad gallera.

Así se podría explicar esta ambivalencia afectiva de los galleros hacia sus gallos, pues, en ciertos momentos, más que la repulsión e incluso animadversión sentida hacia ciertas aves, se expresa por ellas una alta estima: las recogen de la arena casi muertas, las curan y vuelven a preparar, les hablan con cariño y ternura, incluso, en el caso de "Felo", a uno de sus animales le puso el nombre de su amigo recién fallecido ("Caballo"). Es decir, en estas situaciones el gallo trasciende su fase de simple "cosa" intercambiable. Con todo, no se debe olvidar que, los gallos son criados para "pelear", no son mascotas, lo cual los hace entrar y salir de manera casi compulsiva de su fase mercantil.

\section{Conclusiones}

La intención del presente texto ha sido intentar complejizar el fenómeno que se ha llamado socialidad gallera. La crianza y las peleas de gallos en Costa Rica conforman un conjunto de prácticas que han sido exiguamente pensadas. Vistas desde la irracionalidad y calificadas como "salvajes", "incivilizadas" y "crueles", fundamentalmente en el abordaje de los medios de comunicación (Rodríguez y Alpízar, 2014), dichas prácticas sugieren otras perspectivas que van más allá de monocalificaciones e interpretaciones irreflexivas.

El conjunto de normativas explícitas e implícitas que siguen los galleros, algunas asociadas a códigos específicos de honorabilidad y caballerosidad (en ocasiones 
transgredidas), la dinámica de las apuestas, la ambivalencia afectiva con que se interioriza al ave, la vida social del gallo, el tiempo que toma criar a estos animales, el ímpetu y el éxtasis de las personas dentro de un redondel y las manifestaciones variadas de violencias, recrean un panorama profundo (Geertz, 1989) y un enmarañado proceso de significaciones que densifican las relaciones que se establecen en el seno de esta forma cultural, que, en nuestro país data, al menos, de mediados del siglo XIX.

A pesar de las restricciones legales, en muchos escenarios del contexto nacional se siguen jugando gallos, no solo en zonas rurales como pudiera precipitadamente pensarse, sino, en lugares céntricos del Valle Central costarricense. Aun así, la mayoría de redondeles son construidos en sitios alejados de importantes centros poblacionales, en fincas retiradas o espacios privados, sin embargo, la gente de los alrededores sabe muy bien que ahí se juegan gallos; incluso, como relataron varios galleros, los mismos policías conocen la ubicación de estos espacios. Esto problematiza la idea de clandestinidad con que usualmente son referidos estos centros de juego de gallos y la impresión de ocultamiento, malignidad y temor a lo indecible y desconocido referida en los abordajes mediáticos (Rodríguez y Alpízar, 2014).

La socialidad gallera manifiesta entonces dinámicas evidentes de agresividad, que hacen pensar en una síntesis particular: la violencia de la socialidad gallera es una violencia pensada, no puede existir violencia irracional. Más aún, la violencia es en sí, producto de la civilidad, la civilidad es violenta y la gallera, es una violencia sintomática, pero creativa e infinitamente responsable de sí misma. La socialidad gallera no existiría sin violencia; pero se puede ir más allá, la sociedad no existiría sin ella.

Con todo, los gallos y las peleas no son la vida de estos sujetos; al menos no para "Felo" y los jóvenes de La Gotera. Esta es una importante actividad o "deporte”, como ellos la llaman, pero cotidianamente son personas que se dedican a otras actividades, trabajan, estudian, son hijos, padres, esposos, hermanos; es decir, la crianza y peleas de gallos funcionan como una intersección transitada, "un lugar en el que se intersectan un número de procesos sociales distintos", la socialidad gallera no es "un todo autónomo constituido por patrones coherentes, la cultura puede ser concebida como una formación más poderosa de intersecciones donde los procesos se entrelazan dentro de los límites o más allá de estos" (Rosaldo, 1991: 28-31). La crianza y las peleas de gallos no son una totalidad infinita para los galleros, al menos no para los jóvenes de La Gotera; pero sí significan dinámicas importantes en las cuales invierten mucho de su tiempo y dedicación; al respecto su amor-odio por los gallos resulta sugerente.

Finalmente, como se ha apuntado en relación con las dinámicas, tensiones y juegos subterráneos de la socialidad gallera, esta no pretende deformar o subvertir el orden social reinante e instituido: la ética societaria se mantiene intacta, las peleas de gallos funcionan más bien como un conjunto de contraposiciones estéticas, lo cual no es lo mismo que superficiales (sería banalizar la cultura gallera). Con esto se intenta decir que las actividades que se suscitan en los redondeles y más allá de ellos no tienen 
la intención, como quizás lo advierten implícita o explícitamente algunos medios de comunicación, de deconstruir o derogar el ethos de la cultura dominante, su misma conformación cultural reproductora de civilidad (incluso en sus formas de ejercer violencias) imposibilitaría verlas como construcciones antagónicas al orden reinante. Los galleros quieren jugar gallos, y están tan interesados en reproducir la lógica social imperante que pelean y juegan estos animales para no matarse entre sí.

\section{Notas}

1 Este artículo se desprende de una investigación llevada a cabo entre enero de 2012 y julio de 2014 desde la Escuela de Antropología de la Universidad de Costa Rica. El proyecto (N. ${ }^{\circ} 219$ B2-350) se tituló “‘'Se muere gallo bueno!' Jóvenes, galleras y gallos de pelea”.

Una de las primeras menciones acerca de la temática data de la década de 1850. Fernández (1970) publica una crónica del viajero y publicista Wilhelm Marr: "Entre dos perritos tuve la honra de ser presentado al primer jugador de gallos de Costa Rica, el juez de comercio don Juan Bautista Bonilla [personaje de origen español] (...) La pasión del juego de gallos había llegado en él al paroxismo, y más que un hombre parecía una pluma de gallo metida en un frac negro" (Idem.: 170-171). Otra de las publicaciones relacionadas con la temática de los gallos es la de Fernández (1984). Este texto hace referencia al veto a la actividad gallera aprobada por el Congreso de la República: las peleas fueron prohibidas en 1889, legalizadas en 1902, para ser vetadas de nuevo en 1906. Esta última prohibición fue promovida por el que fuera en aquel momento vicepresidente de dicho órgano: Ricardo Jiménez Oreamuno. Lo interesante es que, el propio expresidente Jiménez Oreamuno era un confeso aficionado de las galleras y, además, de la crianza de gallos. En 1912 el Congreso aprobó el decreto que permitía las peleas, lo cual fue pasado al Poder Ejecutivo para su aprobación final. Para el 12 de junio de 1912 el ya presidente Lic. Ricardo Jiménez Oreamuno vetaba dicho decreto (Urbina, 2000). Calistri (1985) refiere algunos datos históricos interesantes; entre ellos, la temprana difusión del juego, manifestada en las antiguas tradiciones imperiales chinas, fenicias, romanas, españolas, portuguesas e inglesas, las cuales difundieron el "espectáculo" hacia países como México, Estados Unidos de América y Francia. Según el autor, el origen de la actividad se ubica en India (1985: 389-400).

Corrales (1997) expone de manera extensa la posición de un gallero acerca de su afición a la crianza y peleas de estas aves. El texto inicia con la pregunta: “iDeporte o juego de azar?" después de la cual no se desarrolla una discusión que permita al lector dirimir sobre una u otra (quizás ambas) alternativa; el autor después de hacer un breve repaso por la significancia del juego en quienes lo practican (sin aportar mayores datos) presenta al entrevistado como "filósofo de las peleas de gallos" quien "contrariamente a lo que pueda pensarse (...) es una persona letrada, con estudios universitarios inconclusos, y por lo que pudimos ver en los "estantes" de la galera, con un gran amor por la lectura" (1997: 2-3).

A pesar de las falencias metodológicas y narrativas del texto de Corrales, es importante mencionar que el aporte de la perspectiva gallera desde la visión de uno de sus practicantes es sumamente sugerente, en primer lugar porque da cierto contexto a las palabras del sujeto y, en segundo lugar, porque se describen varias facetas de las vivencias galleras que son relevantes; por ejemplo, la pasión del gallero (lo que acá llamo socialidad gallera).

Chester Urbina (2000) relaciona las peleas de gallos y corridas de toros con la emergencia del ideario liberal de Estado-nación profesada por la élite burguesa del tiempo, incluso, se relaciona la actividad gallera con el fútbol (actividad que sirvió para hacer más popular la 
imagen de los políticos, por lo cual la élite prefería el fútbol-racional y sofisticado-a las peleas de gallos -sangrientas y decadentes-). La intención de la aristocracia nacional, según Urbina, era establecer políticas sociales que se concentraran en el control y vigilancia de los diferentes sectores subalternos con el fin de "popularizar los valores y prácticas burguesas" (2000: 59).

Finalmente, un par de artículos publicados recientemente (Rodríguez y Alpízar, 2014 y Rodríguez, 2014) se desprenden del trabajo de campo desarrollado para la investigación que da origen al presente texto. El primero de ellos desarrolla una extensa crítica a las diferentes perspectivas que, sobre la actividad gallera, aborda el diario La Nación S. A. Se pone en evidencia los tratamientos apresurados e irreflexivos del medio en cuestión acerca de este tipo de dinámicas, las cuales son consideradas por el matutino como malignas, incivilizadas y tendientes a la degradación social.El segundo (Rodríguez, 2014) intenta explorar algunas realidades experimentadas por un joven gallero en relación con la crianza y peleas de gallos. La forma de evidenciar esta perspectiva se hace a partir del diálogo con "Felo" (el gallero), presentando la entrevista completa que se desarrolló con el joven, mediando algunas breves interpretaciones del autor entre cada acápite. El objetivo del texto es exponer extensamente la lógica de sentido de estas actividades proscritas en la propia narrativa de un sujeto vinculado al "juego".

La mayoría de los textos sobre los cuales se ha hecho mención tienen una particularidad: si bien aportan al conocimiento de la dinámica gallera, adolecen de la cercanía vivencial que brinda el abordaje cualitativo, esto es, la convivencia antropológica-etnográfica. Prácticamente todas estas aproximaciones (a excepción de la de Corrales, 1997 y Rodríguez, 2014) no realizan un acercamiento a la experiencia propiamente dicha de los galleros o de las personas que intervienen en estas actividades, situación que se intenta trascender y discutir en este artículo.

Estos personajes son fundamentalmente hombres. Las mujeres que participan en dichos eventos, según las observaciones etnográficas efectuadas en las galleras, lo hacen de forma pasiva, es decir, acompañan a su pareja a la actividad. Nunca observé una mujer gallera que llegara al redondel a jugar sus gallos.

Lugar de crianza de gallos.

Trabajo informal muy común en algunas zonas de Heredia referido a la venta de ropa y electrodomésticos a domicilio y bajo la modalidad de "a pagos" o a crédito.

Esto es sugerente al respecto de cierta especificidad de las agrupaciones juveniles, las cuales buscan, en la mayoría de los casos, la experimentación de situaciones hedónicas que los hagan salir de la monotonía de los tiempos ordinarios, de esta forma, la manifestación de momentos extáticos (muchas veces cargados de violencia como sucede en las peleas de gallos) suele ser una constante en algunas culturas juveniles (Rodríguez, 2006). Intento decir que este asunto de la adscripción juvenil a una agrupación (efímera o duradera) tiene que ver con la emotividad (Maffesoli, 1996), la cual es una cualidad importante en la conformación-consolidación de estas agregaciones (como se verá más adelante con la socialidad gallera). Se habla de una especie de desvanecimiento del individuo para dar paso a un sujeto colectivo, esto es, una orgía, que supone la reivindicación de la tribu; es, siguiendo a los alquimistas, el glutinum mundi o pegamento universal (Maffesoli, 1996): la razón por la cual ellos permanecen dentro de estas agrupaciones, precisamente, por la promesa de experimentación de novedosas formas de emociones. Esto implica la emergencia de una nueva sensibilidad/subjetividad inscrita en las corporalidades de los muchachos (Rodríguez, 2013). 
Esta conjunción no supone que la vivencia cotidiana de estos jóvenes se resuma en una reivindicación constante de la tribu en donde se pierden las características individuales. Siempre hay irrupciones subjetivas. Además, estos colectivos no viven en un constante carnaval hedónico, también hay espacios para la emancipación, para la crítica y para reflexión (Rodríguez, 2013). Los chicos no se sustraen de la dimensión política, de hecho, manifiestan sus posturas críticas de formas muy creativas, algunas subterráneas; como diría Beck (2006), los jóvenes hoy manifiestan lo político desde lo lúdico y lúdico desde lo político.

Todos los asistentes a la gallera deben cancelar un derecho de entrada a la misma cuando ingresaron al recinto, regularmente, se cobra entre 2000 y 5000 colones dependiendo de la gallera y del evento.

Por ejemplo, "Felo" cuenta la historia de su primer gallo, un animal que cuidó con esmero y que le ganó cerca de 15 peleas, "nunca he tenido un gallo como ese" decía, con cierta melancolía en el rostro, este joven gallero. Evidentemente, las historias de gallos "malos" se comentan poco

Los galleros dicen que estos animales son tremendamente territoriales, según ellos, no puede haber dos gallos en un gallinero, de ser así, se pelean hasta la muerte, a no ser que uno de los dos se corra.

10 Pistola.

11 Persona proveniente de la provincia de Guanacaste.

12 Viene de "picha": en el lenguaje popular costarricense se utiliza para designar al órgano reproductor masculino. En este contexto, "pichazos" remite a "golpes".

Para Bourdieu la sociedad contemporánea acusa una construcción social naturalizada de los géneros, esto es, no se ven las causas y los efectos de estas elaboraciones sociales, simplemente se introyectan desde el ejercicio de una violencia simbólica ("invisible"). Es decir, hay comportamientos masculinos que han sido aprehendidos (de manera generacional) y más allá de esta internalización, han sido naturalizados; de esta forma, los hombres no cuestionan o discuten estas conformaciones de la violencia masculina, puesto que estas ya son de por sí, es decir, ya son parte de sus formas de existencia. Así, estas disposiciones de convivencia se esencializan, conviertiéndose en constructores de identidades estereotipadas y discriminantes (2007: 14, 20, 24, 27 y 32). Así, la "violencia gallera" es naturalizada por los sujetos que participan en dichas dinámicas, al punto de considerar este proceder masculino como natural, lo cual, intersubjetivamente, termina recreando un orden (imperativo masculino de honorabilidad, caballerosidad, etc.) que, como diría Bourdieu, no necesita ser justificado y, por lo tanto, termina siendo incuestionable en sí mismo.

14 En las peleas observadas, las apuestas entre galleros iban desde los 25000.00 (50 USD) y hasta los 150000.00 colones (300 USD).

\section{Bibliografía}

Appadurai, Arjun. La vida social de las cosas. México: Grijalbo, 1991.

Beck, Ulrich.. "Hijos de la libertad: contra las lamentaciones por el derrumbe de los valores". Hijos de la libertad, Ulrich Beck (comp.). México: Fondo de Cultura Económica, 2006.

Bourdieu, Pierre. La dominación masculina. Barcelona: ANAGRAMA, 2007. 
Calistri, Marco. "Historia y difusión delos gallos de pelea". Rivista di Avicultura, 54, 6 (1985): 23-27.

Corrales Arias, Adriano. "La pelea de gallos: entrevista con un gallero anónimo". Revista Fronteras,4(1997): 47-71.

Fernández Guardia, Ricardo. Costa Rica en el Siglo XIX. San José: Editorial Centroamericana, 1970.

Fernández Rivera, Felipe. Los juegos de gallos. Un veto histórico y un discurso parlamentario olvidado. San José: Asamblea Legislativa de Costa Rica, 1984.

Geertz, Clifford. La interpretación de las Culturas. Madrid: Gedisa, 1989.

Maffesoli, Maffesoli. De la orgía, una aproximación sociológica. Barcelona: Ariel, 1996. En el crisol de las apariencias. México: Siglo XXI, 2007.

El tiempo de las tribus. El ocaso del individualismo en las sociedades posmodernas. México: Siglo XXI, 2009.

Rodríguez Aguilar, Onésimo. Entre cánticos y graderías: la construcción de un colectivo juvenil del ámbito futbolístico en Costa Rica. El caso de La Ultra Morada. Tesis de Maestría en Antropología Social. San José: Universidad de Costa Rica, 2006.

. Una tejita rata, pa' evolucionar. Cuadrillas juveniles y barrio en Guararí de Heredia, Costa Rica. Tesis de doctorado en Ciencias Antropológicas. México, D. F., Universidad Autónoma Metropolitana, 2013.

. "Gallos de pelea: algunas precisiones desde el diálogo con un gallero". Cuadernos de Antropología, 24, 1. San José. Universidad de Costa Rica, 2014.

" "Se muere gallo bueno'. Jóvenes, galleras y gallos de pelea". Informe final de investigación. Escuela de Antropología, Universidad de Costa Rica. Inédito.

Rodríguez Aguilar, Onésimo y Natasha Alpízar Lobo. “Las peleas de gallos en la prensa escrita costarricense: un Análisis Crítico del Discurso en algunas noticias del diario La Nación S.A.". Rupturas, 4, 1 (enero-julio, 2014): 50-69.

Rosaldo, Renato. Cultura y verdad. México: Grijalbo, 1991.

Urbina Gaitán, Chester. "Homogenizando culturas". Peleas de gallos, corridas de toros y estado en Costa Rica (1870-1914). Revista de Ciencias Sociales, 89 (2000): 59-67.

Onésimo Rodríguez Aguilar. Costarricense, doctorado en Ciencias Antropológicas por la Universidad Autónoma Metropolitana de México, Distrito Federal. Se desempeña como profesor de la Escuela de Antropología y del posgrado en Antropología de la Universidad de Costa Rica. Es autor de varios artículos publicados en revistas nacionales e internacionales, los temas de interés son: violencia social y culturas juveniles (barras de fútbol, cuadrillas, pandillas, etc.).

Contacto: oneboticario@gmail.com y onesimo.rodriguez@ucr.ac.cr 
